\title{
Complementary and Alternative Medicine in Children with Type 1 Diabetes Mellitus
}

\author{
Belma Haliloğlu1, Pınar Işgüven2, Metin Yıldız2, Ilknur Arslanoğlu3, Müferet Ergüven4 \\ ${ }^{1}$ Marmara University Faculty of Medicine, Department of Pediatric, Division of Pediatric Endocrinology, Istanbul, Turkey \\ 2 Göztepe Education and Research Hospital, Department of Pediatric Endocrinology, Istanbul, Turkey \\ ${ }^{3}$ Düzce University Faculty of Medicine, Department of Pediatric, Division of Pediatric Endocrinology, Duzce, Turkey \\ ${ }^{4}$ Göztepe Education and Research Hospital, Department of Pediatric, Istanbul, Turkey
}

\begin{abstract}
Objective: Complementary and alternative medicine (CAM) is increasingly utilized in adults and children for treatment of various conditions. Studies on CAM in diabetes have mainly focused on the adult population and its application in children has not been well established. The aim of this study was to examine the prevalence and characteristics of CAM use in Turkish children with type 1 diabetes mellitus (T1DM).

Methods: The information was acquired by a questionnaire completed by a face-to-face interview with the parents of children with T1DM.

Results: A total of 195 subjects (mean age: $14.02 \pm 4.7$ years; F/M: 103/92) were included in this survey. Use of CAM was reported in 85 subjects (43.6\%). Herbal medicines were used in 64 subjects (75.3\%). Sixty-nine subjects $(81.2 \%)$ did not inform the diabetes specialist about CAM use. Thirty-eight subjects (44.7\%) evaluated CAM as efficacious. Only 3 subjects (3.5\%) interrupted the insulin injections to use CAM. No relationships were found between CAM use and parental education or insulin dose. There were significant correlations between CAM use and higher family income $(p=0.027)$, urban residence $(p=0.05)$, presence of complications $(p=0.03)$, dissatisfaction with medical therapy $(p=0.034)$ and prior CAM use among parents $(\mathrm{p}=0.001)$.

Conclusion: CAM use is a frequent practice among diabetic children, which is usually not shared with their physicians and sometimes leads to cessation of medical treatment.

Key words: CAM, herbal medicine, type 1 diabetes mellitus

Conflict of interest: None declared

Received: 17.02.2011

Accepted: 21.06.2011
\end{abstract}

\section{Introduction}

Type 1 diabetes mellitus (T1DM) develops in genetically predisposed people as a result of the destruction of the pancreatic beta cells caused by an autoimmune insulitis $(1,2,3)$. At present, the incidence of T1DM is on the increase, while its age of onset decreases $(4,5,6)$. Another worldwide trend noted in recent years is an increase in use of complementary and alternative medicine (CAM). According to the National Institute of Health (USA), CAM is a wide health area which is outside the politically dominant health system in a society or culture in a specific time interval and includes health services, applications, methods, and their accompanying beliefs and theories (7).

Also in Turkey, the use of CAM is increasing in both adults and children. We observed that many individuals suffering from any kind of ailment tend to try various herbs, vitamins, antioxidant agents, yoga, meditation, bioenergy, acupuncture, aroma therapy and prayers in an effort to find a cure for their condition.

The studies about the use of CAM in T1DM children are scarce. The objective of this study was to detect the methods and frequency of use of CAM in T1DM children and to compare those children with a group of controls with regard to variables such as age, sex, insulin requirement, presence of diabetic complications, and sociocultural/ socioeconomic background. The study also aimed to explore the expectations of the families that motivated them to use these treatments.

\section{Address for Correspondence}

Belma Haliloglu MD, Marmara University Faculty of Medicine, Department of Pediatric, Division of Pediatric Endocrinology, Istanbul, Turkey Tel.: +90 21662545 45-9109/9071 E-mail: belmahaliloglu26@hotmail.com

Presented as a poster at LWPES/ESPE $8^{\text {th }}$ Joint Meeting Global Care in Pediatric Endocrinology

(c) Journal of Clinical Research in Pediatric Endocrinology, Published by Galenos Publishing. 


\section{Materials and Methods}

The study was conducted on 200 T1DM patients under the age of 21 who were being followed in the Pediatric Endocrinology Department of Goztepe Education and Research Hospital.

Before the research, an approval was obtained from the Ethics Committee of Goztepe Education and Research Hospital, as per their decision number 55/B, dated March 10, 2009.

The families of the diabetic patients were given information on the aims of the study and they were also told that they were free to leave the study at any time and to refrain from answering some of the questions. CAM was defined as any treatment of a disease which is not included in the biomedical context.

After written informed consent for interviewing and completing the questionnaire forms was obtained from the patients' parents, a questionnaire entitled "Use of alternative medicine in T1DM patients" was filled out by interviewing each family face to face.

Five patients, whose questionnaire forms had been completed fully, were excluded from the study for being unable to answer the questions clearly.

The questionnaire included questions on demographic data (age, education level, socioeconomic status, place of residence), on frequency of use of CAM, method used, how it was used, reason for resorting to CAM, source of information on CAM, time of its initiation, association between CAM use and occurrence of complications, as well as questions on parents' satisfaction with the medical treatment their children were receiving.

\begin{tabular}{lcc}
\hline Table 1. The distribution of CAM methods & & \\
\hline Herbal & $\mathbf{n}$ & $\%$ \\
Prayer & 64 & 75.3 \\
Amulet & 14 & 16.5 \\
Hodja & 1 & 1.2 \\
Exercise & 6 & 7.1 \\
Massage & 12 & 14.1 \\
Vitamins & 2 & 2.4 \\
Special diet & 16 & 18.8 \\
Acupuncture & 2 & 2.4 \\
Bioenergy & 2 & 2.4 \\
Colon hydrotherapy & 1 & 1.2 \\
\hline Total & 1 & 1.2 \\
\hline CAM: complementary and alternative medicine & 85 & 100 \\
\hline
\end{tabular}

T1DM patients who were using CAM and those who were not were compared with respect to the abovementioned data.

NCSS 2007\& PASS 2008 Statistical Software (Utah, USA) program was used for the statistical analysis. During the assessment of the data of the study, besides the descriptive statistical methods (mean, standard deviation, frequency), the Student's t-test was used for the comparison of the quantitative data and normally distributed parameters between the groups. Chi-square test and Fisher's exact chi-square test were applied for the comparison of the qualitative data. The confidence interval of the results was $95 \%$ and the level of significance was taken as a p-value of less than 0.05 .

\section{Results}

The mean age of the patients (103F, 92M) was $14.0 \pm 4.7$ years. $89.2 \% \quad(n=174)$ of the mothers were housewives and $76.4 \%(n=149)$ had attended school for at least five years. $52.3 \% \quad(n=102)$ of the fathers were workers and $68.2 \%(n=133)$ had attended school for at least five years. $48.2 \%(n=94)$ of the families had a monthly income between $\$ 611.62$ and $\$ 1.223 .24$. 89.2\% $(n=174)$ were living in big cities. While no complications related to the diabetic state were reported in $90.8 \% \quad(n=177)$ of the patients, $2.6 \%(n=5)$ had a concomitant chronic disease such as coeliac disease and autoimmune thyroiditis. $4.6 \% \quad(n=9)$

\begin{tabular}{lcc|}
\hline Table 2. The distribution of herbal CAMs & & \\
\hline Stinging nettle & $\mathbf{n}$ & $\%$ \\
Cinnamon & 13 & 20.3 \\
Thyme juice & 13 & 20.3 \\
Black cumin & 16 & 25 \\
Linseed & 7 & 10.9 \\
Pomegranate & 3 & 4.7 \\
Rose hip & 6 & 9.4 \\
Aloe vera & 3 & 4.7 \\
Black fruit herbal & 8 & 12.5 \\
Parsley juice & 3 & 4.7 \\
Oil Leaf & 3 & 4.7 \\
Clove & 4 & 6.3 \\
Others & 4 & 6.3 \\
\hline Total & 33 & 51.6 \\
\hline CAM: complementary and alternative medicine & 64 & 100 \\
\hline
\end{tabular}


of the parents expressed that they were not satisfied with the medical treatment their children were receiving and $29.7 \%(n=57)$ of the parents stated that they had used alternative treatment for themselves previously.

$43.6 \%(n=85)$ of the parents had given alternative treatment besides the medical treatment to their children, while the remaining $56.4 \%(n=110)$ had not. However, $71.3 \%$ $(n=139)$ of the parents commented that they would use these treatments if their children had a malignant condition. Herbal compounds, in particular thyme juice, cinnamon, stinging nettle, aloe vera, were the most frequently mentioned substances used as CAM (Tables 1 and 2).

$64.7 \%(n=55)$ of the parents stated that they applied CAM as a complementary method supporting the medical treatment. $30.6 \% \quad(n=26)$ reported that they got the information from their friends and $29.4 \%(n=25)$ - from their families and close relatives. $31.8 \%(n=27)$ of the patients had begun to use CAM within 3 months of the onset of the disease. $30.6 \%(n=26)$ stated that they had been using CAM for more than one year. Initiation of medical treatment was found to be delayed in $3.5 \% \quad(n=3)$ of the patients and $81.2 \%(n=69)$ of the parents did not share with their doctors that they were using CAM methods. $44.7 \%(n=38)$ of the parents found CAM to be beneficial and $51.8 \% \quad(n=44)$ recommended these methods to others. $48.2 \%(n=41)$ of the parents who used CAM were still using the alternative treatments at the time the questionnaire forms were filled out.

Although no statistically significant association was found between use of alternative treatment in children and education level of parents, the rate of CAM use in big cities was markedly higher than that in small towns $(p<0.05)$. It was also seen that as the level of income increased, the use of CAM in children increased ( $p=0.027)$ (Table 3). The use of alternative treatment was found to be significantly higher in children with diabetic complications or accompanying autoimmune disease as compared to those with no complications $(p=0.030)$. The rate of CAM use was found to be considerably greater in children whose parents were not satisfied with the medical treatment and in children whose parents had previously used alternative treatment for themselves than in those who were satisfied and those who had no experience of CAM $(p<0.01$ and $p<0.01$, respectively).

\section{Discussion}

According to previous studies conducted in Canada, Australia, Denmark and Turkey, nearly half of parents $(8,9,10,16)$ and, to studies conducted in USA and New Zealand, approximately $20-40 \%$ of parents $(11,12,13,14,15)$ reported using one CAM method sometime in their lives.

The number of studies on use of CAM in T1DM patients is limited. Miller et al (17) and Dannemann et al (18) reported that the frequency of CAM use in children with T1DM was $19 \%$ in the USA and $18.4 \%$ in Germany. Even though the rate in our study was found to be relatively higher than that estimated in other countries, this rate was compatible with the results of studies conducted in the general population and in children with chronic disease $(16,19)$, as well as in children with T1DM (36) in Turkey. The high rate of CAM use in our patients may be due to the chronic nature of the disease, its labile course and the complexity of the medical treatments, which may have been the factors that led these parents to search for new ways of treatment to achieve better control $(20,21)$.

In our study, the most frequently mentioned CAM method was administration of herbs. This finding was consistent with the results of some of the studies reported from the USA $(12,14)$ and of many studies from Turkey and other countries $(16,19,22,23,24,25,26,27)$. Dannemann et al (18) found that herbs, homeopathy and vitamins were the most commonly applied CAM methods, while Miller et al (17) noted in their study that religious practices, use of herbs and vitamins were the most frequent ones. In our country, Arikan et al (36) reported that herbs were the most commonly used CAM method (59.6\%), a finding also compatible with our results. Only 4 patients in our study had used homeopathy, naturopathy, or chiropraxy, which are methods more popular in other countries. The high cost of these practices may be the reason why they are not so preferred in Turkey.

As to the type of herb used, Dannemann et al (18) reported that cinnamon and aloe vera were the most commonly used ones, while Arikan et al (36) found that aloe vera, stinging nettle and mulberry were the herbs most frequently given to children with T1DM. In our study, the most commonly administered types were thyme juice, stinging nettle, cinnamon and aloe vera. Others have also reported that cinnamon and aloe vera are especially popular for the treatment of DM $(29,30,31)$.

Although many studies showed that the use of CAM was directly proportional to the education level of the

\begin{tabular}{|c|c|c|c|c|}
\hline & \multicolumn{4}{|c|}{ Use of CAM } \\
\hline & & $\begin{array}{c}\text { Yes } \\
\text { n (\%) }\end{array}$ & $\begin{array}{c}\text { No } \\
\text { n (\%) }\end{array}$ & $\mathbf{p}$ \\
\hline \multirow{2}{*}{$\begin{array}{l}\text { Mother's level } \\
\text { of education }\end{array}$} & Low $^{* *}$ & 69 (42.1) & 95 (57.9) & $\chi^{2}: 0.965$ \\
\hline & $\mathrm{High}^{* * *}$ & $16(51.6)$ & 15 (48.4) & $p=0.326$ \\
\hline \multirow{2}{*}{$\begin{array}{l}\text { Father's level } \\
\text { of education }\end{array}$} & Low & $59(44.4)$ & $74(55.6)$ & $\chi^{2: 0.101}$ \\
\hline & High & $26(41.9)$ & $36(58.1)$ & $p=0.750$ \\
\hline \multirow{2}{*}{$\begin{array}{l}\text { Place of } \\
\text { residence }\end{array}$} & Urban & $80(46.0)$ & $94(54.0)$ & $\chi^{2}: 3.745$ \\
\hline & Rural & $5(23.8)$ & 16 (76.2) & $\mathrm{p}=0.050$ \\
\hline \multirow{4}{*}{$\begin{array}{l}\text { Economic status } \\
\text { (US dollars/ } \\
\text { month) }\end{array}$} & $>1223$ & $5(45.5)$ & $6(54.5)$ & \\
\hline & 611-1223 & $33(60.0)$ & $22(40.0)$ & $\chi^{2: 9.215}$ \\
\hline & $306-612$ & $36(38.3)$ & $58(61.7)$ & $\mathrm{p}=0.027^{*}$ \\
\hline & $<306$ & $11(31.4)$ & $24(68.6)$ & \\
\hline
\end{tabular}


mothers $(14,16,18,28)$ and the level of income of the family $(8,9,18)$, Pitetti et al (11) and Miller et al (17) did not find that these factors had a significant effect. In contrast, Arikan et al (36) observed that the use of CAM decreased as the education level of the mother and the socioeconomic status of the family increased. It was also reported that the use of CAM by the parents themselves was a factor which increased the rate of use of CAM in their children $(16,17,32,33)$. In our study, the use of CAM by the parents themselves was found to be directly proportional to the use of CAM in their children. Although we did not detect any correlation between CAM use and education level of the parents, the use of CAM was found to be significantly higher in families having a high level of income and living in the big cities, a finding consistent with previous studies. We also found that when the parents were asked about using CAM if their children had cancer, the rate of use of CAM would increase from $43.6 \%$ to $71.3 \%$. This result may be indicative of the parents' view about DM as a treatable disease, even if it takes a lifetime. The risk of most complications of DM decreases with an adequate treatment, while cancer is perceived as a much more mortal disease by the families.

The use of CAM was found to be significantly higher in patients with complications and in those with concomitant diseases. This finding may be due to increased anxiety in the parents when faced with a complication or an accompanying disease.

In our study, religious beliefs were found to be important factors encouraging the family to use alternative treatment methods that were mostly applied to support the medical treatment. In our series, there were only 3 families who quit the medical treatment to use CAM. Dannemann et al (18) reported that the most commonly expressed reasons for using CAM was "to try everything" and "their having fewer side effects".

As to source of information about CAM, we found that the majority of the parents had learnt about CAM from their friends and relatives. This finding is compatible with the results of similar studies in our country, while the media and internet are reported as the most common sources of information about the CAM methods in Western countries $(16,34,35)$. In our study, a few patients got the information from their doctors, but only $18.8 \%$ of the families shared this with their doctors. Ozturk et al (16) and Arikan et al (36) reported similar results, while the rate estimated by Dannemann et al (18), for sharing the information on use of CAM with their doctors, was much higher. Also in Dannemann's study, the parents stated that only $37.3 \%$ of the doctors advised their patients to leave the alternative treatment. The patients who did not tell their doctors about the use of CAM commented that their reason for not telling was that their doctors would not understand (18).

In this present study, when the parents were asked their opinion on the use of CAM, half of them said that they found them beneficial. This ratio was reported as $71.7 \%$ by Ozturk et al (16), as $53.8 \%$ by Arikan et al (36), and as $62.5 \%$ by Dannemann et al (18). In all these studies, the issue of usefulness was evaluated by discourse with the families, i.e. subjectively, and was not based on objective criteria such as a decrease in the dosage of insulin or level of $\mathrm{HbA} 1 \mathrm{c}$

Our study indicates that, similar to its practice in other chronic diseases, CAM is frequently used in children with T1DM. As also shown in other studies from Turkey, herbs are the most commonly administered substances in our country. It also appears that when problems occur in the course of the disease, the rate of use of these substances increases. Studies are needed to determine their efficacy, safety, as well as the potential herb-drug or vitamin-drug interactions and to examine the side effects that can occur due to these interactions. In conclusion, pediatricians should communicate with the patients about the CAM methods and inform them about their benefits, harms and possible contraindications.

\section{References}

1. Ozalp I, Tuncer M. Diabetes mellitus in children. Katkı Pediatri Dergisi (Publication of Hacettepe University Medical School, Department of Pediatrics) 1997;18:1-48.

2. Behrman RE, Kliegman RM, Jenson HB. Nelson Textbook of Pediatrics 17th ed. Philadelphia 2004;60:1947-1972.

3. Lifshitz F. Pediatric Endocrinology Fourth edition University of Miami School of Medicine 2003:25/27:611-680.

4. Burden AC, Hearnshow JR, Swift PG. Childhood diabetes mellitus: an increasing incidence. Diabet Med 1989;6: 334-336.

5. Silink M. Handbook of IDDM in childhood and Puberte, 1997.

6. Kumar D, Gemayel WS, Deagen D, Kapadia D, Yamashita $\mathrm{PH}$, Lee M, Dwyer JH, Roy-Burman P, Bray GA, Mack TM. North American twins with IDDM: genetic etiological and clinical significance of disease concordance according to age, zygosity and interval after diagnosis in the first twin. Diabetes 1993;42:1351-1363.

7. National Institute of Health. Panel on definition and description. Defining and describing CAM. CAM Research Methodology Conference. April 1995. Altern Ther and Health Med 1997;3:49-57.

8. Jean D, Cyr C. Use of Complementary and Alternative Medicine in a General Pediatric Clinic. Pediatrics 2007; 120:138-141.

9. Lim A, Cranswick N, Skull S, South M. Survey of complementary and alternative medicine use at a tertiary children's hospital. J Paediatr Child Health 2005;41: 424-427.

10. Madsen H, Andresen S, Gaardskaer RN, Dolmer S, Host A, Damkier A. Use of complementary / alternative medicine among paediatric patients. Eur J Pediatr 2003;162: 334-341.

11. Pitetti R, Singh S, Hornak D, Garcia SE, Herr S. Complementary and alternative medicine use in children. Pediatr Emerg Care 2001;17:165-169. 
12. Sawni-Sikand, Schubiner $H$, Thomas RL. Use of complementary/alternative therapies among children in primary care pediatrics. Ambul Pediatr 2002;2:99-103.

13. Loman DG. The use of complementary and alternative health care practices among children. J Pediatr Health Care 2003;17:58-63.

14. Ottolini MC, Hamburger EK, Loprieato JO, Coleman RH, Sachs HC, Madden R, Brasseux C. Complementary and alternative medicine use among children in the Washington, DC area. Ambul Pediatr 2001;1:122-125.

15. Armishaw J, Grant CC. Use of complementary treatment by those hospitalised with acute illness. Arch Dis Child 1999;81:133-137.

16. Ozturk C, Karayagiz G. Exploration of the use of complementary and alternative medicine among Turkish children. J Clin Nurs 2008;17:2558-2564.

17. Miller J, Binns H, Brickman WJ. Complementary and alternative medicine use in children with type 1 diabetes: a pilot survey of parents. Explore 2008;4-5:311-314.

18. Dannemann K, Hecker W, Haberland H, Herbst A, Galler A, Schäfer T, Brähler E, Kiess W, Kapellen TM. Use of complementary and alternative medicine in children with type 1 diabetes mellitus - prevalence, patterns of use and costs. Pediatr Diabetes 2008;9:228-235.

19. Orhan F, Sekerel BE, Kocabas CN, Sackesen C, Adalioglu $\mathrm{G}$, Tuncer A. Complementary and alternative medicine in children with asthma. Ann Allergy Asthma Immunol 2003;90:611-615.

20. Karayagiz Muslu G, Ozturk C. The complementary and alternative medicine and use in children. Turk $\mathrm{J}$ Pediatr 2008;51-1:62-67.

21. Sinha D, Efron D. Complementary and alternative medicine use in children with attention deficit hyperactivity disorder. J Paediatr Child Health 2005;41:23-26.

22. Oguz S, Pinar R. Which complementary therapies are preferred the most? $1^{\text {st }}$ International \& VIII. National Nursing Conference Proceedings 29 October-2 November, 2000;358-359 (in Turkish).

23. Ceylan S, Hamzaoglu O, Komurcu S, Beyan C, Yalcin A. Survey of the use of complementary and alternative medicine among Turkish cancer patients. Complement Ther Med 2002;10:94-99.
24. Isikhan V, Borazan E, Komurcu S, Ozer A, Arpaci F, Ozturk $\mathrm{B}$, et al. Alternative therapies used by cancer patients. XV. National Cancer Conference Abstract Book, 23-27 April, Antalya, Turkey. 2003; p. 61.

25. Tas F, Karagol H, Ustuner Z, Yazar A, Can G, et al. Prevalence and indicators of complementary and alternative therapies used by cancer patients in Turkey. XV. National Cancer Congress Abstract Book, 23-27 April, Antalya, Turkey, 2003; p.58.

26. Gozum S, Tezel A, Koc M. Complemantary alternative treatments used by patients with cancer in Eastern Turkey. Cancer Nurs 2003;26:230-236.

27. Sanders H, Davis MF, Duncan B, Meaney FJ, Haynes J, Barton LL. Use of complementary and alternative medical therapies among children with special health care needs in Southern Arizona. Pediatr 2003;111:584-587.

28. Spigelblatt L, Ammara LG, Pless BI, Guyver A. The use of alternative medicine by children. Pediatrics 1994;94: 811-814.

29. Khan A, Safdar M, Ali Khan M, Khattak KN, Anderson RA. Cinnamon improves glucose and lipids of people with type 2 diabetes. Diabetes Care 2003;26:3215-3218.

30. Ghannam N, Kingston M, Al-Meshaal IA, Tariq M, Parman NS, Woodhouse N. The antidiabetic activity of aloes: Preliminary clinical and experimental observations. Horm Res 1986;24:288-294.

31. Ajabnoor MA. Effect of aloes on blood glucose levels in normal and alloxan diabetic mice. J Ethnopharmacol 1990;28:215-220.

32. Davis FM, Meaney JF, Duncan B. Factors influencing the use of complementary and alternative medicine in children. J Altern Complement Med 2004;10:740-742.

33. Ernst E. The role of complementary and alternative medicine. BMJ 2000;321:1133-1135.

34. Algier L, Hanoglu Z, Ozden G, Kara F. The use of complementary and alternative medicine in cancer patients in Turkey. Eur J Oncol Nurs 2005;9:138-146.

35. Paltiel O, Avitzour M, Peretz T, Cherny N, Kaduri L, Pfeffer RM, Wagner N, Soskolne V. Determinants of the use of complementary therapies by patients with cancer. J Clin Oncol 2001;19:2439-2448.

36. Arikan D, Sivrikaya SK, Olgun N. Complemantary alternative medicine use in children with type 1 diabetes mellitus in Erzurum, Turkey. J Clin Nurs 2009;18:2136-2144. 